\title{
Health, Disability, AND Well-Being ${ }^{1}$
}

\author{
S.AndrewSchroeder(aschroeder@cmc.edu) \\ Claremont McKenna College \\ draft of 2 January 2015 , \\ forthcoming in the Routledge Handbook of Well-Being, ed. Fletcher
}

The relationship between health and well-being is a vexed one. On the one hand, it seems obvious that the two go hand-in-hand. Common sense tells us that illnesses, diseases, and injuries are bad for us. We call these instances of ill health, and we describe ourselves as suffering from them. We worry about having health problems, and we feel sorry for those who do. Parents who fail to prevent sickness or disability in their children are accused of harming them and are labeled negligent. There are, of course, some times we may welcome illness, disease, or injury: the flu may get us out of an exam for which we're unprepared, asthma may excuse us from military service, and a broken leg from an accident may net us a large insurance settlement. But in cases like these, it seems clear that each health problem is itself a bad thing that merely happens to be accompanied by something good enough to outweigh the bad. (We would prefer to get out of the exam without catching the flu, avoid military service without asthma, and get a large sum of money without breaking our leg.) So, there seems to be a strong assumption that health problems reduce well-being - that is, that they are bad for the people who suffer from them - unless perhaps that badness is outweighed by an accompanying good. ${ }^{2}$

Not surprisingly, the academic literature generally endorses this assumption. When philosophers need an example of something that makes a life go worse, they frequently choose a health problem. In discussing the non-identity problem, for example, Kavka uses the example of a handicapped child (1982: 98; cf. Parfit 1984: 367-9), and Harman (2004) a deaf child. In contexts where health and well-being are more direct topics of discussion, the same assumption is stated more explicitly:

To be disabled in any sense is not the same as being differently abled. Being deaf for example is... a condition which harms the individual relative to freedom from deafness. (Harris 2001: 383; cf. McMahan 2005: 96)

\footnotetext{
${ }^{1}$ I thank Daniel Groll, Daniel Hausman, Paul Hurley, Adrienne Martin, Nicole James Ross, and Nancy Schroeder for very helpful comments on earlier drafts of this chapter.

${ }^{2}$ Throughout this chapter, I will use "X's well-being," "X's welfare," and "good for X" interchangeably.
} 
Philosophers writing on well-being sometimes include health as a constituent of well-being (Kraut 2007: 132-3; Murphy 2001: 100-5; Finnis 1980: 85-6) and regard it as a serious objection to desire-based theories of well-being that those theories don't give health intrinsic value (Raibley 2013; Lauinger 2013). Most of the epidemiological and health economic literature treats ill health as something of importance primarily because of its impact on well-being. (See e.g. Broome 2002; Neumann 2005: 9.) Accordingly, the major economic measures used to evaluate overall health are given names like the Quality of Well-Being Scale, the Health Utility Index, and the EuroQoL [Quality of Life]. Finally, many states, such as homosexuality, that were previously thought to be diseases or illnesses became recognized as compatible with health, once we learned that they are not bad for their possessor. ${ }^{3}$

All of this, then, points to a strong connection, in both everyday and academic discourse, between ill health and reductions in well-being. Diseases, injuries, and illnesses are bad for us, and that is the primary reason why we should be concerned about them. Set against this, however, is what has been called the Disability Paradox: many people with what most of us would consider serious disabilities and health problems, such as deafness, paraplegia, and kidney disease, report surprisingly high levels of well-being (Albrecht and Devlieger 1999; Ubel et al. 2005; Angner et al. 2013) perhaps as high as the self-reported well-being of people in full health (Riis $e t$ al. 2005). Some claim they would refuse treatments to restore their health (Hahn and Belt 2004) and go to great expense to conceive children who share their condition (Sanghavi 2006). Even if well-being is lower for those in ill health, some advocates for the disabled argue that that is not because disabilities are themselves bad. Rather, any reduction in well-being is primarily attributable to unjust social factors (Oliver 1996). Disability is in this respect like being a woman, having dark skin, or being gay: these traits are not in any way intrinsically bad or harmful, though in an unjust and discriminatory society like ours, they may in fact tend to reduce well-being.

What, then, should we conclude about the connection between health and well-being? None of the observations in the previous paragraph is sufficient to show that health isn't tightly connected to well-being. (Survey participants might misrepresent their own levels of well-being, people in ill health might refuse treatments out of a concern for something other than personal well-being, etc.) But, taken together, they do give us reason to question the strength of the relationship. In the remainder of this chapter I will investigate the link between health and well-being. I will argue that for a

\footnotetext{
${ }^{3}$ The complete explanation for how homosexuality came to be recognized as non-pathological is a complex and ongoing one. But the American Psychiatric Association's decision, for example, to remove homosexuality from the Diagnostic and Statistical Manual of Mental Disorders (DSM-II) was in part motivated by research showing that most people who were gay did not experience distress or social impairments as a result of their sexual orientation (Lamberg 1998).
} 
wide range of health states, the connection is a contingent one. Further, empirical findings suggest that decrements in health probably have much less impact on well-being than most people suppose. This has important consequences for issues of justice and morality.

\section{Preliminaries}

Before we can look at the relationship between health and well-being, a few preliminaries are necessary. First, there are no generally-accepted theories of well-being or of health. Ideally, therefore, this chapter would begin by discussing the many alternative theories of well-being and health that have been offered, since what relationship there is between the two may depend on what analysis of those concepts we accept. Fortunately, I think we can make progress without engaging in that arduous task. In this chapter, I won't take a stand on the nature of well-being, except that I will set aside certain theories (mentioned above) which explicitly include health as a component of well-being. (On those theories, the relationship between health and well-being is straightforward.)

When it comes to health, I will assume that it is a matter of proper functioning: healthy eyes are eyes that work the way eyes are supposed to, a healthy immune system is one that works as immune systems are supposed to, and so forth. Decrements in health, which include injury, illness, disease, and disability — or, for short, pathology — occur when part of an organism is functioning improperly in a way that is in some relevant sense inferior. This analysis of health is, I think, our everyday one, and it is standard in medical usage (Wakefield 1999) and economic analysis (Hausman 2010: 281-2). It is also consistent with most philosophical theories of health. (What distinguishes many theories of health is how they cash out the idea of "proper" functioning. Contrast, e.g. Boorse (1997), Wakefield (1992), and Venkatapuram (2013). I won't worry about differences among these views, since in most ordinary cases their judgments of pathology and health coincide.)

This general analysis of health may seem to be controversial. The ears of a deaf person and legs of a paraplegic are, on any plausible account, not functioning properly. Therefore, according to the above analysis, deafness and paraplegia are pathological. Many advocates for the disabled, however, have argued that disability is compatible with health. The U.S. Centers for Disease Control, for example, say, "Having a disability does not mean a person is not healthy or that he or she cannot be healthy" (CDC 2014). This is a complex issue which I cannot fully discuss here, except to say that I believe such claims are often made out of a desire to avoid certain implications that commonly accompany health judgments: for example, that health problems call for medical treatment, or that they are undesirable 
(Bickenbach 2013; Wendell 2001). Note that neither of those claims follows from the analysis of health I am using. Given that the ears of a deaf person are functioning improperly, it does not follow that the proper response is surgery on the ears. It could be that the appropriate response is to change the environment (to make it more easily navigable for the deaf), or to do nothing at all. Similarly, even if the ears of a deaf person function poorly compared to the ears of a hearing person, it does not follow that the life of a deaf person is in any respect worse than the life of a hearing person. So, even if my account of health is controversial, I believe it has the potential to address many of the worries that motivate attempts to reject it.

This leads to the second preliminary point. In what follows, much of the literature I cite concerns disability, rather than health. That is because much more has been written about the relationship between disability and well-being than about the relationship between health and well-being. Since standard examples of disability will straightforwardly count as pathologies on the account of health I am working with, we can use the literature on disability to draw conclusions about health. But we should keep in mind that disability is only one type of pathology. ${ }^{4}$

\section{The EfFECTS OF ILl HeALTH}

Ill health, or pathology, can manifest itself in a number of ways, but two seem most prominent. First, ill health can cause pain or another negative phenomenological state. Some pathologies necessarily involve this. You can't have a headache without experiencing pain, and you can't have an anxiety disorder without experiencing distress. Many other pathologies, like bee stings and late-stage cancer, typically involve pain, but need not. Finally, many pathologies, like blindness, involve no pain at all, and others, such as lactose intolerance, involve pain that can be avoided through medical intervention or behavioral modification.

The second way ill health manifests itself is through limitations on what we can do. This is obvious in the case of musculoskeletal conditions (e.g. a broken hand) and sensory limitations. But it is also true of things like infectious diseases. In addition to the discomfort it causes, the flu affects your respiratory system and causes weakness and fatigue, all of which prevent you from engaging in many activities you otherwise could. At the limit, health conditions that are fatal prevent us from engaging in any activities at all.

\footnotetext{
${ }^{4}$ What distinguishes disability from other sorts of pathology? The question is a controversial one, but the common understanding of disability requires at least that disability be long-lasting and perhaps relatively stable over time. So the flu, sunburns, and paper cuts would be examples of pathologies that are not disabilities.
} 
So, there are two primary ways that ill health affects us: it can cause pain, and it can restrict our capabilities. ${ }^{5}$ The connection between the former and well-being is the clearer of the two. On nearly any account of wellbeing, pain and distress generally reduce well-being. This is true by definition on a hedonic theory, but other plausible theories of well-being will also make pain a detriment to well-being. We can imagine some situations where pain itself might be good - it might be good to feel distress at the loss of a loved one - but the pain resulting from pathology doesn't seem to be like this. There are also cases where on balance pain can be a good. A friendship might be forged through shared suffering, or a painful experience might spur one to change one's lifestyle for the better. But these seem like the case of the flu excusing one from an exam. The pain here is still bad; it is just accompanied by a good which outweighs it.

A stronger challenge to the claim that pain is bad comes from Wendell: "[L]iving with pain, fatigue, nausea, unpredictable abilities, and/or the imminent threat of death creates different ways of being that give valuable perspective on life and the world... Some of us would choose to live them even if they were inseparable from the suffering" (2001: 31). If it is true that there are valuable perspectives that one can gain only through pain, then this case may be importantly different than the flu and the exam. The flu and the exam are separable in a way that pain and the associated perspective would not be. At the most, though, Wendell's example could show that pain is sometimes not a bad, not that it is generally good. (Wendell seems to accept this.) So I will set this argument aside, in order to turn to the other primary way ill health affects us: by restricting our capabilities. Its connection to well-being is much less clear.

\section{RESTRICTED CAPABILITIES AND WELL-BEING}

Focus, for now, on people living with health problems that prevent them from engaging in certain activities. (We will consider mortality at the end of this section.) What is the effect of that capability loss on a person's well-being? It may initially seem like it must be a bad thing for the person. After all, most of us don't like to have our options taken away. But a little reflection shows that this needn't be so. Mark Twain is reported (erroneously, it seems) ${ }^{6}$ to have said, "The man who does not read has no

\footnotetext{
${ }^{5}$ The idea that the two salient manifestations of ill health are pain and restrictions on capabilities is a common one, embodied in many health measurement and classification systems. The Health Utilities Index (Mark 3), for example, classifies health states by their impact on two phenomenal dimensions (emotion and pain) and six activity dimensions (vision, hearing, speech, ambulation, dexterity, and cognition).

${ }^{6}$ http://quoteinvestigator.com/2012/12/11/cannot-read/
} 
advantage over the man who cannot read." As a point about well-being, this seems right (Silvers 2003: 479). The well-being of a committed vegetarian need not decrease due to a shellfish allergy. So the first point to note is that ill health which restricts a capability that would not have been exercised need not have any effect on well-being.

This point, though, may seem to be of limited importance. Many health problems impact capabilities - movement, sight, cognition - which nearly everyone who is able to exercises in some way. Does the loss of a capability that a person would have exercised lead to a loss of well-being? Again, it is obvious that it need not. If the movie you plan to see is sold out, the effect on your well-being will depend on what you do instead. If your second-choice movie is inferior to your first, then your well-being will decline. But your second-choice movie may instead end up being more entertaining and enlightening than your first-choice, increasing your wellbeing. Or perhaps missing out on the movie leads you to stay home and catch up on housework, increasing your well-being in the long run.

This point may seem obvious and uninteresting. Of course being prevented from pursuing an option you would have pursued need not make you worse off. Whether it does will depend on what replaces the foregone option. Nevertheless, when we think about disability, our first thought is usually only of the valuable activities disability can bar us from. The blind person is unable to fully appreciate a brilliant painting. The paraplegic is unable to play soccer. The diabetic may not be able to enjoy an afternoon of wine tasting. Art, athletic competitions, and fine wine are all things that many people enjoy for their own sakes. If disability prevents us from doing these things, that seems like a huge loss. We have, after all, been barred from a legitimately valuable thing. But the above reflections show that that such a conclusion is premature. Before knowing whether losing access to these goods will reduce a person's well-being, we need to know what she will replace them with. If they are replaced with equally valuable substitutes, then the person's well-being will be unaffected. For most of the valuable things that can be taken away by disability, this seems possible. Music and sculpture are no less valuable than painting. Wheelchair basketball can be just as exciting and intense as soccer. And so forth (Moller 2011: 199). ${ }^{7}$ While it is true, therefore, that disabilities frequently exclude people from valuable activities and experiences, that exclusion need have no impact on their well-being.

\footnotetext{
${ }^{7}$ Moller expresses concern that there may be a loss of well-being when the substituted good does not come from the same general class as the lost one. So, he worries that not being able to hear music may reduce well-being. If there is something to Moller's claim, it seems to me he has made the classes too narrow. So long as someone who loses access to music is capable of some form of artistic experience, I see no reason to think there must be a loss of well-being. But this issue warrants further discussion.
} 
The other main concern people have when thinking about disability is the impact that disability will have on activities people engage in not primarily for their own sake, but for other purposes. Call these things, which for many people include cooking dinner, driving a car, going shopping, or taking a shower, instrumental activities. When we are prevented from engaging in an instrumental activity, our goal usually isn't to find an equally valuable alternative; it is to find an alternative way of accomplishing the same goal that is comparably efficient. Anecdotal evidence suggests that, for many people with disabilities, this is possible if the environment is arranged properly. $^{8}$ (In cases where the environment isn't arranged well -- e.g. a city with no curb cuts for wheelchairs -- it may be plausible to maintain that the resulting reduction in well-being can be attributed primarily to unjust social factors, rather than to the disability itself. $)^{9}$

What all of this shows is that the loss of capabilities that accompanies ill health need not reduce well-being. For most lost capabilities, we can imagine equally valuable substitutes for activities engaged in for their own sake, and equally efficient means of carrying out instrumental activities. Of course, in particular circumstances the alternatives may not be available. The clarinetist, forced by arthritis to resign from an orchestral career, may not be able to find a substitute that she finds as fulfilling. And even when equally valuable substitutes are available, there is no guarantee that people will take advantage of them. The extent to which the capability loss that accompanies ill health reduces well-being is therefore a contingent matter. It depends on how often, in fact, people are able to find equally valuable substitutes and equally efficient alternatives.

Since this is, at least in part, an empirical matter, we should turn to the empirical sciences for guidance. The relevant empirical research, though, is difficult to interpret. The social scientists who have studied this, usually

\footnotetext{
${ }^{8}$ I am not aware of any studies that attempt to document this from an academic perspective. But a large number of books, articles, and documentaries show people with what most would consider serious disabilities managing instrumental activities with no more difficulty than anyone else. Angner $e t$ al. (2013) sometimes appear to claim that disease disrupts daily functioning and, as a result, happiness. But what their study in fact shows is that people who report having their daily activities disrupted by ill health are less likely to be happy. And, surprisingly, their study found that objective measures of ill health were not significantly associated with disruption of daily activities. Thus, their study is consistent with the claim that many people with disabilities have little difficulty with instrumental activities, and accordingly no resultant loss of happiness.
}

${ }^{9}$ There are also a number of respects in which health problems may tend to improve well-being. On certain plausible views of well-being, there is value in overcoming obstacles or accomplishing difficult tasks. By providing such obstacles, ill health could increase well-being. Illness and disability can force us to see the world in a different way, providing us with a valuable perspective inaccessible to those in good health (Wendell 2001; Barnes 2009: 341). Finally, some research suggests that people experience anxiety when faced with a large number of good options (Shenhav and Buckner 2014). By eliminating some valuable options, a disability could therefore reduce anxiety. (Think of the anxiety you might feel when faced with several job offers that all appear to be equally good. If the offers really are equally good, it might have been better for you to have received only one such offer.) 
called the process of adaptation to disability and ill health, often aren't sensitive to alternative theories of well-being. And, more importantly, wellbeing is difficult to measure. ${ }^{10}$ There is no consensus on what well-being is, nor are there any uncontroversial, reliable indicators of it. That said, it seems likely that people unable to find good substitutes and alternatives would tend to report their happiness as being lower than the self-reported happiness of people in full health. The best empirical studies, however, find that once they have had time to adapt to their state, people with a wide range of disabilities report levels of happiness much higher than expected, sometimes as high as the self-reported happiness of people in full health (Riis et al. 2005). This continues to hold when researchers attempt to control for factors (such as lowered expectations, self-deception, etc.) that might tend to distort people's self-reports (Ubel et al. 2005). ${ }^{11}$

Of course, despite researchers' best efforts, it is still possible that the self-reports are biased in some way. And according to most theories of wellbeing, well-being is more than felt happiness, so it is possible that the wellbeing of people in ill health could be low, even if their happiness is high. But these results nevertheless make a strong prima facie case that the wellbeing of people with disabilities is much higher than most people assume. We know that, at least in many cases, equally valuable substitutes for lost activities are available. People with disabilities are telling us that they are happy and satisfied with their lives, suggesting that they believe they have found those valuable substitutes. We should work from the (defeasible) assumption that they have (Goering 2008).

Before moving on to discuss the consequences of this result, we should briefly consider death resulting from ill health. The analysis here is quite simple. We've seen that the loss of capability resulting from ill health need not lower well-being, when good substitutes and alternatives can be found. But, since death involves the loss of all capabilities, we know no such substitutes and alternatives will be available. So, death will reduce well-being for anyone who otherwise would have experienced a life that was on balance good. I will, optimistically and I hope accurately, assume that this is true of most premature deaths.

\section{HEALTH AND JUSTICE}

\footnotetext{
${ }^{10}$ See Hausman (2015) for a discussion of some of these difficulties, in the context of health.

${ }^{11}$ I know of no studies that attempt to determine which health problems can be most successfully adapted to. See Frederick and Loewenstein (1999), however, for a survey of factors that can make successful adaptation more or less likely. There is also some research suggesting that depression is an exception to the Disability Paradox: people suffering from depression tend to rate depression as worse than the general public does (Pyne et al. 2009).
} 
Most people think health is an important concern of justice and even a basic human right (Daniels 2007: ch.2). Most wealthy countries and many poorer ones provide universal health care to their citizens. People are offended when they see heath inequalities within a population (Anand, Peter, and Sen 2004; Eyal et al. 2013). Why does health occupy such a significant place in our thinking about justice? The natural and dominant explanation is that health is so important because it has a large impact on well-being. We need to show a special concern for health because it is a significant determinant of how well people's lives go. Health inequalities are unjust because they mean that some segments of a population are living much better lives than others. We've seen, however, that there is reason to question this. It is true that pain and premature mortality reduce well-being, but longterm capability loss may not have a large effect on well-being. (It often will have some effect, and the process of adaption to a disability involves a temporary loss of well-being. But these losses are relatively small, compared to the well-being losses that most people assume accompany chronic ill health.) Should we, then, say that justice requires only managing pain and extending life, but doesn't require much beyond that when it comes to health? Should public insurance plans stop paying for expensive surgeries to increase mobility or address sensory limitations?

To reject this conclusion - which most find extremely counterintuitive - we need a different justification for making health a concern of justice (Loewenstein and Ubel 2008; Moller 2011; Shakespeare 2013: 100). Two basic alternatives have been proposed. The first looks to preferences. Even if people in ill health are just as happy as people in good health, we know that most people strongly prefer not to be in ill health. If justice involves respecting or catering to people's preferences, then it would require working to prevent and reverse health problems when possible. So far, so good. This approach faces a potential problem, however. Why do people prefer not to become disabled? If the explanation is that they think that disability would make them much less happy, then their preference for health is suspect because it is based on a belief that is probably false. Why should we go to such great lengths to satisfy preferences that are based on false beliefs? Indeed, many desire-based theories of well-being argue that it is the satisfaction of informed desires that make one's life go better (Sidgwick 1981: 110-1).

Loewenstein and Ubel (2008) respond to this worry by listing a number of respects in which one can have a rational preference for something that won't increase one's happiness. If we accept Mill's (1863) distinction between higher and lower pleasures, for example, then a cognitive disability that led one to replace poetry with push-pin might leave one's quantity of happiness unaffected, while nevertheless making one worse off. Thus, it would be rational to prefer not having the cognitive disability, while nevertheless recognizing that such a disability would not make one any less 
happy. In addition to the idea of higher pleasures, Loewenstein and Ubel cite the value of experiencing a range of emotions, participating in meaningful activities, and having a range of options (even if one won't exercise those options).

Each of these points potentially helps to justify a preference-based concern for some aspects of health. But much more argument is needed before this sort of view could ground anything like our current attitudes towards health. The primary problem is that Loewenstein and Ubel's criteria don't apply to most health problems. ${ }^{12}$ Someone who is blind or a paraplegic or a diabetic, for example, is just as capable as anyone else of enjoying higher pleasures, experiencing a range of emotions, and engaging in meaningful activities. The only criterion which will be triggered by most health problems is the (possible) value of having a range of options. I will return to this below.

Moller (2011) offers a much narrower version of the preference-based approach. He accepts that many types of ill health will have minimal effect on one's happiness and well-being, but nevertheless thinks that it can be rational to prefer to avoid disability. He offers a comparison with love. I might recognize that I would be equally well-off if I were married to someone other than my wife. I would (after a period of adjustment) be just as happy, engage in equally meaningful and fulfilling pursuits, and so forth. But, despite this, loving my wife means valuing my relationship with her, and therefore resisting any change to that relationship (201). Someone who was prepared to sever a relationship simply because an objectively better partner came along couldn't be said to truly love her original partner. Moller suggests that something like this happens in the case of disability. As we've seen, adapting to disability may involve substituting some valuable activities (e.g. painting) for others (music). Truly valuing something, however, means being attached to it and therefore resisting anything that would require one to give it up. If I am a music-lover, I should resist anything that would force me to replace it with a different art form. I can rationally do this while at the same time recognizing that after making the switch to painting, I would be just as well-off as I was before.

Moller's argument seems like it could provide an alternative justification for some of our current beliefs about the importance of health, and it catches a wider range of health problems than Loewenstein and Ubel's suggestions. Unfortunately, though, in its current form it can't justify our common-sense view of the importance of health. Many resources go towards preventing ill health in children, who haven't yet developed the values and attachments upon which Moller's argument depends.

\footnotetext{
${ }^{12}$ In fairness to Loewenstein and Ubel, their suggestions are intended to address problems raised for public policy by adaptation in many areas of life - not just health. The proposals they offer may be more useful in those other contexts.
} 
It is worth looking, therefore, to a very different response to the problem, offered by Hausman and Daniels. (In what follows, I will gloss over the important differences in Hausman's and Daniels' views.) According to standard liberal theories of justice, government should remain neutral on the question of what constitutes a good or valuable life. Accordingly, it is not society's job to see to the general well-being of its members; its job is instead to provide them with a space in which to live whatever lives they choose. If this liberal picture of the proper role of government is correct, then a concern for health should not be based on its impact on well-being, since promoting well-being is not the proper aim of public policy. Instead,

[T] he evaluation of a health state should depend on the extent to which its characteristics and consequences diminish the range of good lives and valuable projects that are available to people. From a public perspective, the significance of bad health lies not in ultimate outcomes, but in the extent to which it diminishes capabilities. (Hausman 2010: 287, cf. Daniels 2007: 27)

We know that ill health, even if it doesn't impact well-being, can nevertheless impact the capabilities people have, so this seems like a compelling justification for regarding health as a matter of justice.

To see what kind of a concern for health this approach would yield, we need to know which "valuable projects" and "range of good lives" it is important for society to make available to people. As Hausman notes,

The goal of social policy is not, however, to expand the range of activities that are available to individuals without reference to the importance of the activities. Providing individuals with a wider choice of religions is more important than providing them with a wider selection of breakfast cereals. (2010: 287)

This leads to a problem. How can we declare one set of projects or range of lives more valuable than another, consistent with liberalism? Aren't these precisely the issues about which the liberal state is supposed to remain neutral?

Depending on the version of liberalism one holds, this need not be the case. Perfectionistic versions of liberalism justify liberal neutrality with reference to a substantive account of value. According to Raz (1987), for example, neutrality follows from the importance of allowing people to autonomously choose from a range of valuable options. The state ought to remain neutral among the many different ways of life that are objectively valuable, but needn't be neutral concerning ways of life that are not objectively valuable. If religious observance is an important component of certain objectively valuable lives, but eating breakfast cereals is not, then the 
state could justifiably give higher priority to health needs that would conflict with religious practice than to health needs that would conflict with eating breakfast cereals. ${ }^{13}$

According to political versions of liberalism, the state is not to appeal to a substantive conception of value, so this solution is not available. Nevertheless, a political liberal might still justify a preference for certain ways of life over others, if that preference was agreed on by all reasonable parties - that is, if it was the subject of a Rawlsian overlapping consensus (Rawls 1993: 133-72). Hausman says that the importance of an option will be relative to a given society, and he expresses optimism that within a society there will be broad agreement on such issues (Hausman 2010: 287, cf. Daniels 2007: 35-36, 50-52). Perhaps, then, he means to take this route. Regardless, however, the question of how to determine the importance of different options is a difficult one that neither Hausman nor Daniels has fully resolved.

If something like Hausman's or Daniels' proposal is the right way to justify making health a concern of justice, a number of important conclusions follow. Here, I will briefly mention one, emphasized by Hausman (2010; 2015). Cost-effectiveness analyses are used in many parts of the world to determine what treatments are covered by public insurance plans. These analyses typically measure effectiveness in quality-adjusted life years (QALYs), interpreted as quantifying the well-being associated with various health states. If Daniels or Hausman is correct, these analyses are measuring effectiveness in the wrong way. If we want to continue using cost-effectiveness analyses to guide public policy, we need to modify the QALY so that, instead of measuring the well-being associated with health states, it instead measures the political value of the options or activities that ill health bars us from. Hausman (2015: ch. 14) has sketched one way in which this might be done, but no system of this sort has yet been developed in detail. Any such system would constitute a major departure from current practices.

\section{HEALTH AND ETHICS}

In addition to raising issues of justice, health also holds an important place in our thinking about personal morality. Consider, for example, the parent-child relationship. Most of us believe that parents have a special

\footnotetext{
${ }^{13}$ We could imagine a related view according to which health has intrinsic value because it is intrinsically valuable that people have more options available to them. (This view could, but need not, be liberal.) In order to avoid running afoul of some of the arguments offered earlier, such a view would be most plausible if it allowed that increasing options didn't itself increase a person's well-being. In other words, such a view would say that it is good that Jane is healthy, although it is not necessarily good for Jane that she be healthy. (Sen sometimes sounds like he might hold a view like this. See e.g. his (1999: 189-90).) I thank Paul Hurley for suggesting this possibility to me.
} 
obligation to see to the health of their children. Parents who allow their children to become sick or injured, or who fail to inculcate healthy habits in their children, are seen as negligent. But if blindness, for example, doesn't significantly reduce well-being, why should we condemn a parent who declines to have her newborn treated with erythromycin, an inexpensive eye ointment that can prevent infection leading to blindness (Barnes 2009: 347)? This is not an idle question. Some parents with disabilities like deafness and achondroplasia (dwarfism) seek to conceive children who share their condition. Fertility clinics face difficult questions about whether to aid them in these pursuits (Sanghavi 2006).

This puzzle is, of course, the personal analog of the political question we discussed in the previous section. Unfortunately, we can't simply import either of the earlier solutions wholesale. Preference-based views, like Loewenstein's, Ubel's, and Moller's, will run into trouble because children frequently will have no well-formed preferences about their health. If we instead ask what the child would want if she had a well-formed preference, or if we ask what an advocate for that child would want on her behalf, we run into further problems because disabilities can sometimes be identityconstituting. A child who grows up with a disability or chronic health problem may have experiences so different from those she would have had if healthy, that it is plausible to say that she becomes a different person (Goering 2008: 129; Shakespeare 2013: 99). There is thus no clear perspective from which to ask what the child would want.

Liberal approaches like Daniels' and Hausman's are potentially of more use, but they also can't be directly transposed to this case. We certainly wouldn't want to say that parents have no obligation to promote their child's well being. But the other aspect of the liberal view does seem relevant. Parents plausibly have a responsibility to prepare their children for a range of possible life plans, rather than narrowly channeling them towards a particular career or lifestyle. Feinberg calls these the "anticipatory autonomy rights" of children - or, more eloquently, the "child's right to an open future" (1992: 77). Since ill health closes off valuable opportunities, this seems a plausible way to ground a parental obligation to promote a child's health.

Of course, as in the political case, there is still the difficulty of specifying which possible life plans a parent should try to keep open. Preparing a child to pursue one possible career often precludes adequately preparing her to pursue another, so we can't ask parents to keep all options open. Feinberg sometimes writes as if parents should seek to provide children with as many options as possible (1992: 84), but it is unclear what this means and why we should value quantity over quality (Archard 2011). It therefore appears that we will have to engage in substantive normative reasoning to determine which life plans a parent should try to keep open for 
her child. ${ }^{14}$ This task looks similar to the one facing Hausman and Daniels in the political sphere, but it is important to recognize that it is distinct. The parent-child relationship is not directly analogous to the government-citizen relationship, so there is no reason that the opportunities a parent should preserve for her children must be the same as the opportunities a state has an obligation to provide for its citizens. Also, parents have extensive obligations to look out for their children's welfare, whereas states (on the liberal view) don't have a similar obligation to see to the welfare of their citizens. That suggests that in the parent-child relationship, considerations of welfare will frequently compete with the obligation to maintain an open future. Given both of these factors, it seems likely that if we adopt an opportunity-based view of the importance of health, the health-related obligations of the state may be quite different than the health-related obligations of parents.

\section{CONCLUSION}

Most people think that health is a significant determinant of well-being. If you get sick, injured, or disabled, that is a very bad thing for you. This common view is usually correct when it comes to conditions that involve significant pain or that cause death. But many kinds of ill health primarily or exclusively affect us by restricting our capabilities. When it comes to this sort of health problem, we have good reason to believe that the common view is often wrong. Many conditions of this sort appear to have a relatively small impact on well-being, at least once a person has had time to adapt to her situation. More research needs to be done, especially to determine how well people adapt to specific health states, but the results so far suggest that we need to rethink our stance towards health, at both the individual and societal level. There may be ways to justify the strong interest that we take in preventing and treating non-painful, non-fatal pathologies, but those justifications will have to look very different from the well-being-based justifications that are usually offered, and in any case they have yet to be fully explored.

\footnotetext{
${ }^{14}$ Ebels-Duggan (forthcoming) argues for a similar claim, discussing a Feinberg-type view in the context of education. In order to distinguish the issues on which we may appropriately aim to teach our children a particular view (e.g. the theory of gravity, the wrongness of gratuitous murder) from the issues on which we should aim to have them make up their own minds (e.g. the desirability of certain occupations), she argues that we must make substantive normative judgments.
} 


\section{REFERENCES}

Albrecht, G. and Devlieger, P. (1999) "The disability paradox: high quality of life against all odds," Social Science and Medicine, 48, pp. 977-88.

Anand, S., Peter F., and Sen, A. (eds) (2004) Public Health, Ethics, and Equity, Oxford: Oxford University Press.

Angner, E., Ghandhi, J., Purvis, K.W., Amante, D., and Allison, J. (2013) "Daily Functioning, Heath Status, and Happiness in Older Adults," Journal of Happiness Studies, 14, pp. 1563-74.

Archard, D. (2011) "Children's Rights," in E. Zalta (ed) The Stanford Encyclopedia of Philosopby (Summer 2011 edition), available at http://plato.stanford.edu/archives/sum2011/entries/rights-children/.

Barnes, E. (2009) “Disability, Minority, and Difference," Journal of Applied Philosophy, 26(4), pp. 337-55.

Bickenbach, J. (2013) 'Disability, 'Being Unhealthy,' and Rights to Health,' Journal of Law, Medicine, and Ethics, 41(4), pp. 821-8.

Boorse, C. (1997) "A Rebuttal on Health," in J. Humber and R. Almeder (eds), What is Disease?, Totowa, NJ: Humana Press, pp. 1-134.

Broome, J. (2002) "Measuring the burden of disease by aggregating well-being," in C. Murray, J. Salomon, C. Mathers, and A. Lopez (eds) Summary Measures of Population Health: Concepts, Ethics, Measurement and Applications, Geneva: World Health Organization, pp. 91-114.

Centers for Disease Control (2014) "Disability and Health: Healthy Living," available at http:// www.cdc.gov/ncbddd/disabilityandhealth/healthyliving.html, accessed 13 September 2014.

Daniels, N. (2007) Just Health: Meeting Health Needs Fairly, Cambridge: Cambridge University Press.

Ebels-Duggan, K. (forthcoming) "Educating for Autonomy: An Old-fashioned View," Social Philosophy and Policy.

Eyal, N., Hurst, S., Norheim, O., and Wikler, D. (eds) (2013) Inequality in Health: Concepts, Measures, and Ethics, Oxford: Oxford University Press.

Feinberg, J. (1992) “The Child's Right to an Open Future," in Freedom and Fulfillment: Philosophical Essays, Princeton: Princeton University Press, pp. 76-97.

Finnis, J. (1980) Natural Law and Natural Rights, Oxford: Oxford University Press.

Frederick, S. and Loewenstein, G. (1999) "Hedonic Adaptation," in D. Kahneman, E Diener, and N. Schwartz (eds), Scientific Perspectives on Enjoyment, Suffering, and Well-Being, New York: Russell Sage Foundation, pp. 302-29.

Goering, S. (2008) “You Say You're Happy, But...': Contested Quality of Life Judgments in Bioethics and Disability Studies," Bioethical Inquiry, 5, pp. 125-35

Hahn, H. and Belt, T. (2004) "Disability Identity and Attitudes Toward Cure in a Sample of Disabled Activists," Journal of Health and Social Behavior, 45, pp. 453-64.

Harman, E. (2004) "Can We Harm and Benefit in Creating?" Philosophical Perspectives, 18, pp. 89-113.

Harris, J. (2001) "One principle and three fallacies of disability studies," Journal of Medical Etbics, 27, pp. 383-7.

Hausman, D. (2015) Valuing Health: Well-Being, Freedom, and Suffering, Oxford: Oxford University Press.

(2010) "Valuing Health: A New Proposal," Health Economics, 19, pp. 280-96

Kavka, G. (1982) “The Paradox of Future Individuals" Philosophy and Public Affairs, 11(2), pp. 93-112.

Kottke (1982) "Philosophic Considerations of Quality of Life for the Disabled," Arcbives of Physical Medicine and Rehabilitation, 63(2), pp. 60-62.

Kraut, R. (2007) What is Good and Why, Cambridge, MA: Harvard University Press.

Lamberg, L. (1998) "Gay is Okay With APA - Forum Honors Landmark 1973 Events," Journal of the American Medical Association, 280(6), pp. 497-9.

Lauinger, W. (2013) “The Missing-Desires Objection to Hybrid Theories of Well-Being," The Southern Journal of Philosophy, 51(2), pp. 270-95.

Loewenstein, G. and Ubel, P. (2008) "Hedonic adaptation and the role of decision and experience utility in public policy," Journal of Public Economics, 92, pp. 1795-1810.

McMahan, J. (2005) "Causing Disabled People to Exist and Causing People to Be Disabled," Etbics, 116(1), pp. 77-99.

Mill, J.S. (1863) Utilitarianism, London: Parker, Son, and Bourn, West Strand.

Moller, D. (2011) "Wealth, Disability, and Happiness," Philosophy and Public Affairs, 39(2), pp. 177-206.

Murphy, M. (2001) Natural Law and Practical Rationality, Cambridge: Cambridge University Press. 
Neumann, P. (2005) Using Cost-Effectiveness Analysis to Improve Health Care, Oxford: Oxford University Press.

Oliver, M. (1996) Understanding disability, from theory to practice, London: Macmillan.

Parfit, D. (1984) Reasons and Persons, Oxford: Oxford University Press.

Pyne, J.M., Fortney, J.C., Tripathi, S., Feeny, D., Ubel, P., and Brazier, J. "How Bad Is Depression? Preference Score Estimates from Depressed Patients and the General Population," Heath Services Research, 44(4), pp. 1406-23.

Raibley, J. (2013) "Health and well-being," Philosophical Studies, 165, pp. 469-89.

Rawls, J. (1999) A Theory of Justice (revised edition), Cambridge, MA: Harvard University Press.

- (1993) Political Liberalism, New York: Columbia University Press.

Raz, J. (1987) "Autonomy, Toleration, and the Harm Principle," in R. Gavison (ed), Issues in Contemporary Legal Philosophy, Oxford: Oxford University Press, pp. 313-33.

Riis, J., Loewenstein, G., Baron, J., Jepson, C., Fagerlin, A., and Ubel, P. (2005) "Ignorance of Hedonic Adaptation to Hemodialysis: A Study Using Ecological Momentary Assessment," Journal of Experimental Psychology, 134(1), pp. 3-9.

Sanghavi, D. (2006) "Wanting Babies Like Themselves, Some Parents Choose Genetic Defects," The New York Times, 5 December 2006.

Sen, A. (1999) Development as Freedom, New York: Anchor Books.

Shakespeare, T. (2013) "Nasty, Brutish, and Short? On the Predicament of Disability and Embodiment," in J. Bickenbach, F. Felder, and B. Schmitz (eds), Disability and the Good Human Life, Cambridge: Cambridge University Press, pp. 93-112.

Shenhav, A. and Buckner, R. (2014) "Neural correlates of dueling affective reactions to win-win choices," Proceedings of the National Academy of Sciences, 111(30), pp. 10978-10983.

Sidgwick, H. (1981/1907) The Methods of Ethics (7th ed.), Indianapolis: Hackett.

Silvers, A. (2003) "On the Possibility and Desirability of Constructing a Neutral Conception of Disability," Theoretical Medicine, 24, pp. 471-87.

Ubel, P., Loewenstein, G., Schwarz, N., and Smith, D. (2005) "Misimagining the Unimaginable: The Disability Paradox and Health Care Decision Making," Health Psychology, 24(4), pp. S57-S62.

Venkatapuram, S. (2013) "Health, Vital Goals, and Central Human Capabilities," Bioethics, 27(5), pp. 271-9.

Wakefield, J. (1992) “The Concept of Mental Disorder," American Psychologist, 47, pp. 373-88.

- (1999) "Evolutionary Versus Prototype Analyses of the Concept of Disorder," Journal of Abnormal Psychology 108(3), pp. 374-99.

Wendell, S. (2001) "Unhealthy Disabled: Treating Chronic Illnesses as Disabilities," Hypatia, 16(4), pp. 17-32. 